\section{Novidades da Revista Brasileira de Atividade Física e Saúde para 2014}

\author{
Airton José Rombaldi ${ }^{1,2}$ \\ Alex Antonio Florindo 1,3 \\ José Cazuza de Farias Júnior ${ }^{1,4}$
}

1. No mês de janeiro de 2014, submetemos a Revista Brasileira de Atividade Física e Saúde para a avaliação da SciELO, candidatando o periódico ao processo de indexação nessa base de dados. Neste momento, está ocorrendo o processo de análise;

2. A partir da número 2/2014, teremos modificações na nominata dos Editores. O Prof. Dr. Mauro Virgílio Gomes de Barros (UPE), após dois anos de exercício na função de Editor Chefe, deixa a função e para ocupar a editoria foi convidado o Prof. Dr. José Cazuza de Farias Júnior, da Universidade Federal da Paraíba (que exercia anteriormente a função de Editor Associado). Neste sentido, queremos em nome da área da atividade física e saúde brasileira, agradecer o trabalho realizado pelo Prof. Mauro, o qual deixa a RBAFS para tocar outros projetos que necessitam de acompanhamento integral. Os Profs. Drs. Alex Antonio Florindo (USP) e Airton José Rombaldi (UFPel) completam o trio de Editores Chefes da RBAFS.

Além da mudança na posição de Editor Chefe, para dar conta da tarefa de editorar um crescente número de submissões à RBAFS, foram convidados três colegas para exercerem a função de Editores Associados. São eles: Prof. Dr. Mathias Roberto Loch (UEL); Prof. Dr. Marcelo Cozzensa da Silva (UFPel) e Prof. Dr. Cassiano Ricardo Rech (UFSC), aos quais agradecemos e desejamos boas-vindas ao grupo de editores;

3. Novas normas de publicação (instruções aos autores) foram produzidas e, assim que estiver concluído o processo de tradução para o inglês e para o espanhol, serão disponibilizadas na plataforma da RBAFS. Entre as mudanças introduzidas nas novas normas de publicação, duas merecem destaque:

- a Seção especial "Programas de pós-graduação da área 21" mudará de nome e de objetivo. Passará a se chamar "Pesquisa e pós-graduação em atividade física e saúde", a qual deixará de aceitar somente a divulgação dos Programas de pós-graduação que trabalham com a temática de atividade física e saúde da área 21 da CAPES, para ser mais abrangente, passando a aceitar, independente da área de avaliação da CAPES, a contribuição de qualquer curso de pós-graduação que trabalhe com a temática da atividade física relacionada à saúde. Neste sentido, cabe salientar o objetivo da nova seção especial "a seção especial é destinada à veiculação de artigos apresentando experiências de pesquisa e de formação de pesquisadores. Interessam para esta seção as contribuições que descrevam modos de organização de grupos de pesquisa ou de trabalho em rede com vistas ao desenvolvimento de projetos de pesquisa e ações de formação ou capacitação de recursos humanos para investigação em atividade física e saúde."

- a partir da publicação das novas normas da RBAFS, não serão mais aceitas revisões narrativas. A partir de 2014, aceitaremos, para percorrer o fluxo editorial, somente revisões sistemáticas.
Rev Bras Ativ Fis Saúde p. 1-1 DOI

http://dx.doi.org/10.12820/rbafs.v.19n1p1

1 Editor Chefe da Revista Brasileira de Atividade Física \& Saúde

2 Universidade Federal de Pelotas

3 Universidade de São Paulo

4 Universidade Federal da Paraíba 